\title{
COMPARATIVE EVALUATION OF BUTORPHANOL AND FENTANYL FOR EPIDURAL ANALGESIA IN LOWER LIMB SURGERIES
}

\author{
Tejinderpal Kaur Grewal'1, Simrit Kaur², Balwinder Kaur³, Parmod Kumar', Sandeep Kaur Sidhu ${ }^{5}$ \\ 1 Professor, Department of Anaesthesia, Government Medical College and Rajindra Hospital, Patiala, Punjab. \\ ${ }^{2}$ Assistant Professor, Department of Anaesthesia, Government Medical College and Rajindra Hospital, Patiala, Punjab. \\ 3 Professor, Department of Anaesthesia, Government Medical College and Rajindra Hospital, Patiala, Punjab. \\ 4 Professor and HOD, Department of Anaesthesia, Government Medical College and Rajindra Hospital, Patiala, Punjab. \\ 5Junior Resident, Department of Anaesthesia, Government Medical College and Rajindra Hospital, Patiala, Punjab.
}

\section{ABSTRACT}

\section{BACKGROUND}

Epidural and spinal blocks are major regional techniques with a long history of effective use for a variety of surgical procedures and pain relief. Epidural block with the catheter technique gives a better control of the level of analgesia and can be used for providing post-operative pain relief by opioids or local anaesthetic agents.

The purpose of the present study was to compare the safety and efficacy of epidural butorphanol versus epidural fentanyl as adjuvants to bupivacaine for lower limb surgeries.

\section{MATERIALS AND METHODS}

100 patients were randomised into two groups with 50 patients in each group: Group BB- epidural administration of $20 \mathrm{~mL} 0.5 \%$ plain bupivacaine with [1 mg $(1 \mathrm{~mL})$ butorphanol $+1 \mathrm{~mL} \mathrm{NS}=2 \mathrm{~mL}$ ]. Group BF- epidural administration of $20 \mathrm{~mL} 0.5 \%$ plain bupivacaine with $100 \mathrm{mcg}(2 \mathrm{~mL})$ of fentanyl.

Settings and Design- Randomised double-blind trial.

\section{RESULTS}

The mean onset of sensory blockade and time for maximum sensory blockade was observed to be significantly reduced with the addition of fentanyl to bupivacaine as compared to butorphanol and bupivacaine. The results showed statistically significant increase in the duration of analgesia with the addition of fentanyl to bupivacaine as compared to butorphanol and bupivacaine.

\section{CONCLUSION}

We can conclude that butorphanol and fentanyl were effective adjuvants to bupivacaine when used epidurally in patients undergoing lower limb surgery. Although, epidural fentanyl with bupivacaine produces significantly faster onset of sensory blockade compared to epidural butorphanol; however, epidural butorphanol with bupivacaine produces significantly prolonged duration of analgesia compared to epidural fentanyl.

\section{KEYWORDS}

Fentanyl, Butorphanol, Epidural, Bupivacaine.

HOW TO CITE THIS ARTICLE: Grewal TK, Kaur S, Kaur B, et al. Comparative evaluation of butorphanol and fentanyl for epidural analgesia in lower limb surgeries. J. Evolution Med. Dent. Sci. 2018;7(15):1845-1848, DOI: 10.14260/jemds/2018/417

\section{BACKGROUND \\ Epidural and spinal blocks are major regional techniques} with a long history of effective use for a variety of surgical procedures and pain relief. Epidural block with the catheter technique gives a better control of the level of analgesia and can be used for providing post-operative pain relief by opioids or local anaesthetic agents.[1]

Local anaesthetics are the mainstay of therapy for obtaining analgesia or anaesthesia with an epidural. Specifically, factors such as surgical location and duration desire to have a sensory and/ or motor block or the expected potency and duration of a specific local anaesthetic agent should be considered prior to placing an epidural block. [2]

'Financial or Other Competing Interest': None.

Submission 23-02-2018, Peer Review 22-03-2018,

Acceptance 28-03-2018, Published 09-04-2018.

Corresponding Author:

Dr. Simrit Kaur,

Assistant Professor, Department of Anaesthesia,

Government Medical College and Rajindra Hospital,

Patiala, Punjab.

E-mail: drsimrit29@gmail.com

DOI: $10.14260 /$ jemds $/ 2018 / 417$

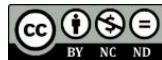

Local anaesthetics act by producing a reversible blockade of sodium channels in nervous tissue preventing the transmission of electrical impulses and produce sympathetic blockade.[2]

Adjuvant analgesics (co-analgesics) contribute significantly to pain relief when used either alone or in combination with other analgesics. Neuraxial adjuvants are used to improve or prolong analgesia and decrease the adverse effects associated with high doses of a single local anaesthetic agent. In addition to their dose sparing effects, neuraxial adjuvants are also utilised to increase the speed of onset of neural blockade (reduce latency), improve the quality and prolong the duration of neural blockade. Sedation, stable haemodynamics and an ability to provide prolonged post-operative analgesia are the main desirable qualities of an epidural adjuvant. Butorphanol is a potent analgesic with both opioid agonist and antagonist effect. Butorphanol and its major metabolites are agonist at kappaopioid receptors and mixed agonist-antagonists at mu opioid receptors. ${ }^{[3]}$

Fentanyl, a highly lipid soluble, pure mu agonist with rapid onset and short duration of action has been used with various local anaesthetics for wide variety of surgical 
procedures. Fentanyl is highly lipophilic, rapidly diffuses out of epidural space and much of fentanyl analgesic effect is mediated by systemic absorption rather than spinal receptor binding. These highly lipid soluble agents as fentanyl are associated with rapid dermatomal spread, rapid onset and low incidence of pruritis or nausea and can be potentiated by epinephrine.[4] Epidural fentanyl caused segmental analgesia when administered as a bolus and non-segmental systemic analgesia when administered continuous infusion.

The purpose of present study was to compare the safety and efficacy of epidural butorphanol versus epidural fentanyl as adjuvants to bupivacaine for lower limb surgeries.

\section{MATERIALS AND METHODS}

After Institute's Ethical Committee approval and informed written consent from patients, 100 patients of both genders aged 18 - 60 years, ASA grade I and II admitted for lower limb surgeries were enrolled into the present study. Those patients who had any anatomical abnormalities of spine, local skin infection or cellulitis, coagulation disorders or associated neurological or cardiovascular disorders were excluded from the study.

Study Design- Randomised controlled double-blind trial.

\section{Randomisation}

Eligible patients underwent randomisation after providing written informed consent. The random sequence of allocation code (Intrathecal analgesia group or systemic analgesia group) was obtained from a random number table of integers. This random number table of integers was constructed using a computer generated random number function in Libre Office Calc version 5.0.3.2. Randomised and blinded allocation of patients to the study drugs was achieved by assigning concealed random number codes to patients at the time of enrolment. Labels indicating intrathecal analgesia group or systemic analgesia group were sealed in opaque, numbered envelopes. The concealed randomised allocation codes (patient's group assignment) was known only to the principal investigator and the anaesthesia care givers, but not to the post-operative assessors or the patients or the statistician.

100 patients were randomised into two groups with 50 patients in each group: Group BB- epidural administration of $20 \mathrm{~mL}$ of $0.5 \%$ plain bupivacaine with $[1 \mathrm{mg}(1 \mathrm{~mL})$ butorphanol $+1 \mathrm{~mL} \mathrm{NS}=2 \mathrm{~mL}$. Group BF- epidural administration of $20 \mathrm{~mL} 0.5 \%$ plain bupivacaine with 100 mcg $(2 \mathrm{~mL})$ of fentanyl.

Patients were familiarised with the visual analogue scale (VAS) (0- No pain, 10- Worst pain) 1 day before surgery and asked to grade their pain on this scale.

\section{Visual Analogue Scale (VAS) ${ }^{[5]}$}

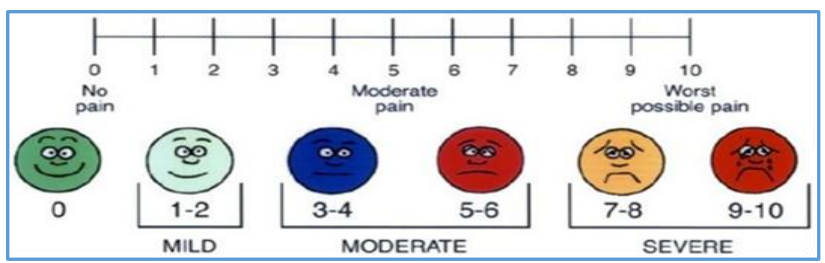

During pre-anaesthetic check-up, a detailed history and thorough general, physical and systemic examination (CVS, chest, CNS, renal) was done. Patients were advised overnight fasting and Tab. Ranitidine $150 \mathrm{mg}$ and Tab. Lorazepam $1 \mathrm{mg}$ orally was given as premedicants 6 am in the morning on the day of surgery. In the operation room, after attaching routine monitors (Electrocardiogram, non-invasive blood pressure, pulse oximeter), intravenous access was secured with 18-G cannula. All patients were preloaded with $20 \mathrm{~mL} / \mathrm{kg}$ of Ringer's lactate solution.

After proper positioning, back was cleaned with antiseptic solution and draped. Local anaesthetic $1-2 \mathrm{~mL}$ of $2 \%$ xylocaine was injected subcutaneously at L3 - L4 space. Sise introducer was introduced and taken out. The epidural space was identified using 18-G disposable Tuohy's needle with loss of resistance technique at L3 - L4 interspace. Then 18-G Portex epidural catheter will be passed through the epidural needle in upward direction and threaded $3-4 \mathrm{~cm}$ inside the epidural space. The needle was withdrawn slowly, and the catheter was fixed to the back using adhesive tape. A test dose of $3 \mathrm{~mL}$ of $2 \%$ lignocaine with adrenaline was given after initial negative aspiration for blood and cerebrospinal fluid. Then, $20 \mathrm{~mL}$ of $0.5 \%$ plain bupivacaine along with one of the two study drugs was injected into the epidural space.

Group BB- Epidural administration of $20 \mathrm{~mL} 0.5 \%$ plain bupivacaine with [1 $\mathrm{mg}(1 \mathrm{~mL})$ butorphanol $+1 \mathrm{~mL} \mathrm{NS}=2$ $\mathrm{mL}$.

Group BF- Epidural administration of $20 \mathrm{~mL} 0.5 \%$ plain bupivacaine with fentanyl $100 \mathrm{mcg}$ [2 $\mathrm{mL}]$.

Blood pressure (systolic, diastolic and mean), heart rate, respiratory rate and peripheral oxygen saturation $\left(\mathrm{SpO}_{2}\right)$ were recorded 5 minutes before the epidural injection (0) and at 5, 10, 15, 20, 25 and 30 minutes after the injection, and subsequently every 15 minutes till the end of surgery. Hypotension (defined as systolic blood pressure of less than $90 \mathrm{mmHg}$ or less than $20 \%$ of baseline blood pressure) was treated with intravenous fluid initially and appropriate doses of intravenous mephentermine, if required. Bradycardia (defined as heart rate of less than 60) was treated with intravenous $0.6 \mathrm{mg}$ atropine sulfate.

Sensory block was assessed by pinprick method. The level of sensory blockade was assessed every two minutes till blockade at $\mathrm{L}_{1}$ level was achieved.

\section{Onset of Sensory Blockade}

It was taken from the completion of injection of study drug till the patient does not feel pinprick at $\mathrm{L}_{1}$ level.

\section{Time for Maximum Sensory Blockade}

It was taken as the time from the completion of injection of study drug to maximum sensory blockade attained (i.e. till two consecutive readings of sensory block remain the same, i.e. highest cephalad spread of sensory block occur).

Onset of motor blockade was assessed at 5-minute intervals till 30 mins (i.e. B5, B10, B15, B20, B25 and B30) according to the Modified Bromage Scale ${ }^{[6]}$ :

1- Complete block (Unable to Move Feet or Knees).

2- Almost complete block (Able to Move Feet Only).

3- Partial block (Just able to Move Knees).

4- Detectable weakness of hip flexion while supine (Full Flexion of Knees). 
5- No detectable weakness of hip flexion while supine.

6- Able to perform partial knee bend.

\section{Onset of Motor Block}

It was taken from the completion of the injection of study drug till the patient developed Modified Bromage Scale grade 4 motor blockade.

\section{Time for Maximum Motor Blockade}

It was taken from the completion of the injection of study drug till the patient developed Modified Bromage Scale grade 1 motor blockade.

Grade of sedation during surgery was assessed by the Modified Ramsay's Sedation Scale[7] every 5 mins till 30 mins and then every 15 mins till end of surgery.

Post-operatively, assessment of pain was done with the help of VAS score, every hour till 6 hrs. and every 2 hrs. till 24 hrs. and vitals were recorded at the same time intervals. Duration of analgesia was taken as the time from onset of analgesia upto time when VAS reached 5 . Patient was then given rescue analgesic (Butorphanol $2 \mathrm{mg}$ in $10 \mathrm{~mL}$ of normal saline in BB Group and fentanyl $100 \mathrm{mcg}$ in $10 \mathrm{~mL}$ of normal saline in BF Group) through epidural catheter and study in that patient was ceased. The epidural catheter was kept for $24 \mathrm{hrs}$. in post-operative period and post-operative analgesia will be maintained with epidural top-ups on patient's demand. Complications such as nausea, vomiting, urinary retention, headache, pruritus and respiratory depression were noted and treated accordingly.

Statistical Analysis: Analysis was conducted using IBMM SPSS Statistics (version 22.0). Numerical data was expressed as mean and standard deviation and statistical analysis was done using the independent ' $\mathrm{t}$ ' test, chi-square test and MannWhitney $U$ test to compare the two groups. The ' $p$ ' value of $<0.05$ was considered statistically significant and the ' $p$ ' value of $<0.001$ was considered statistically highly significant.

Sample size was estimated based on pilot study. We see that mean difference in SBP in 2 groups was 5.3 with SD of 9.05. With this our sample size $n=46$ per group at a power of $80 \%$ and confidence interval of $95 \%$. For possible dropouts, it was decided to include 50 patients per group. Alpha $=0.05$, $\mathrm{z}(1$-alpha/2) $=1.95996$, beta $=0.20$ Power $=1$-beta $=0.80$, $\mathrm{z}(1$-beta $)=0.84162$, sigma $=9.05$, delta $=5.3 \mathrm{n}=46$ per group. $\mathrm{N}=(\mathrm{Z}$ alpha $/ 2+\mathrm{Z} \beta) 2 * 2 * \sigma 2 / \mathrm{d} 2$, where $\mathrm{Z}$ alpha/2 is the critical value of the normal distribution at $/ 2, Z \beta$ is the critical value of the normal distribution at $\beta, \sigma 2$ is the population variance and $\mathrm{d}$ is the difference between 2 means.

\section{RESULTS}

A total of 100 patients for lower limb surgery were enrolled for the study and were randomly divided into two groups. The demographic characteristics in both the groups exhibited marked similarities and did not show any statistical significant difference $(p>0.05)$. Table 1 shows the demographic profile of various patients.

As shown in Table 2, the onset of sensory block was faster in Group BF with mean $4.92 \pm 1.14$ as compared to Group BB with mean $5.80 \pm 0.95$ and this difference was statistically highly significant as the ' $p$ ' value was $<0.001$. The time for maximum sensory block was faster in Group BF with mean $15.60 \pm 1.39$ as compared to Group BB with mean $17.60 \pm$
1.76 and this difference was statistically highly significant as the ' $p$ ' value was $<0.001$. The onset in Group BF was $21.10 \pm$ 1.13 minutes and in Group BB was $20.84 \pm 1.69$ and time for maximum motor blockade was $29.32 \pm 2.13$ in Group BF and $29.56 \pm 1.75$ minutes and the difference was statistically not significant as the ' $p$ ' value was $<0.05$. In Table 3 duration of analgesia was $7.64 \pm 1.39$ in Group BB and 6.04 \pm 1.29 in Group BF and it was statistically highly significant as the ' $\mathrm{p}$ ' value was $<0.001$

\begin{tabular}{|c|c|c|c|}
\hline $\begin{array}{c}\text { Demographic } \\
\text { Characters }\end{array}$ & $\begin{array}{c}\text { Group } \\
\text { BB }\end{array}$ & $\begin{array}{c}\text { Group } \\
\text { BF }\end{array}$ & P value \\
\hline Age (year) & $39.34 \pm 12.69$ & $39.16 \pm 13.27$ & 0.939 \\
\hline Height (cm) & $164.12 \pm 4.99$ & $162.57 \pm 5.93$ & 0.160 \\
\hline Weight (kgs) & $68.74 \pm 5.00$ & $67.96 \pm 5.74$ & 0.471 \\
\hline Male/ Female & $41 / 9$ & $37 / 13$ & 0.334 \\
\hline $\begin{array}{c}\text { Mean Duration of } \\
\text { Surgery (mins) }\end{array}$ & $105.10 \pm 15.40$ & $107.40 \pm 13.52$ & 0.429 \\
\hline \multicolumn{4}{|c|}{ Table 1. Demographic Profile } \\
\hline
\end{tabular}

\begin{tabular}{|c|c|c|c|}
\hline Block Characteristics & Group BB & Group BF & P value \\
\hline $\begin{array}{c}\text { Onset of sensory block } \\
\text { (mins) }\end{array}$ & $5.85 \pm 0.95$ & $4.92 \pm 1.14$ & $<0.001$ \\
\hline $\begin{array}{c}\text { Maximum duration of } \\
\text { sensory block (mins) }\end{array}$ & $17.60 \pm 1.76$ & $15.60 \pm 1.39$ & $<0.001$ \\
\hline $\begin{array}{c}\text { Onset of motor block } \\
\text { (mins) }\end{array}$ & $20.84 \pm 1.69$ & $21.10 \pm 1.13$ & 0.553 \\
\hline $\begin{array}{c}\text { Maximum duration of } \\
\text { motor block (mins) }\end{array}$ & $29.32 \pm 2.13$ & $29.56 \pm 1.75$ & 0.763 \\
\hline \multicolumn{4}{|c|}{ Table 2. Comparison of Sensory and Motor Block } \\
Characteristics \\
\hline
\end{tabular}

\begin{tabular}{|c|c|c|c|}
\hline Groups & Group BB & Group BF & P value \\
\hline $\begin{array}{c}\text { Duration of } \\
\text { Analgesia }\end{array}$ & $7.64 \pm 1.39$ & $6.04 \pm 1.29$ & $<0.001$ \\
\hline \multicolumn{3}{|c|}{ Table 3. Duration of Analgesia (hrs.) } \\
\hline
\end{tabular}

\section{DISCUSSION}

Epidural anaesthesia offers superior pain relief and early mobilisation. It also improves the post-operative outcome and attenuates the physiological response to surgery, in particular significant reductions in pulmonary infections, pulmonary embolism, ileus, acute renal failure and blood loss. Addition of opioids to bupivacaine leads to faster onset of sensory blockade and prolonged duration of analgesia. The dose-sparing action of local anaesthetics and stable cardiovascular parameters make it a very effective adjunct in regional anaesthesia.

In present study, mean time for onset of sensory block was $5.80 \pm 95$ mins In BB Group and $4.92 \pm 1.14$ mins in BF Group. Statistically, the difference in time of onset of analgesia was highly significant [p value $<0.001$ ]. Our results are in concordance with Kaur et al comparing epidural butorphanol AND fentanyl as adjuvants in the lower abdominal surgery. It was shown that mean time for onset of sensory block in BB (Bupivacaine Butorphanol group) was $5.50 \pm .91$ mins AND BF was $4.92 \pm 1.03$ mins.[8] Similar results were obtained by Kumar et al,[9] Sharma et al[10] and Nupoor et al.[11]

In present study, time for maximum sensory block was $17.6 \pm 1.76$ mins in BB Group and 13.9 \pm 20 mins in BF Group. Statistically, the difference in time for maximum sensory block was highly significant [p value $<0.001$ ]. Kaur et al in 2014 compared butorphanol $1 \mathrm{mg}$ and fentanyl $100 \mathrm{mcg}$ as 
adjuvants to bupivacaine in lower abdominal surgeries and demonstrated time for maximum sensory blockade (Completion of analgesia) was $11.80 \pm 1.63$ mins in butorphanol group and $10.80 \pm 1.25$ mins in fentanyl group. However, their definition of time for maximum sensory blockade is different from our study. They defined it as time from the onset of analgesia to maximum sensory blockade attained, whereas we defined it as time from the completion of injection of study drug to maximum sensory blockade attained. ${ }^{[8]}$ Our results are in concordance with those given by Hunt et al.[12]

In present study, mean time of onset of motor blockade was $20.84 \pm 1.69$ mins in butorphanol group and $21.10 \pm 1.13$ in fentanyl group, which was statistically non-significant. Kaur et al in 2014 compared epidural butorphanol and fentanyl as adjuvants in lower abdominal surgery and found mean onset of motor block in butorphanol group was $20.56 \pm$ 2.04 mins and fentanyl (100 ug) was $20.76 \pm 1.6$ mins. ${ }^{[8]}$ The results of present study were consistent with Kumar et al and Chattopadhyay et al. The time for maximum motor blockade in present study in butorphanol group was $29.32 \pm 2.13$ mins and $29.56 \pm 1.75$ mins in fentanyl group. The difference in mean value of these two groups is non-significant.

In study conducted by Kaur et al, the mean time for maximum motor blockade was $8.68 \pm 1.06$ mins in butorphanol group and $8.72 \pm 0.79$ mins in fentanyl group. The results of our study are not in concordance with the above study, because in Kaur et al study time for maximum motor blockade was taken from onset of motor blockade, while in our study it was taken from injection of study drug.

In present study, mean duration of analgesia in butorphanol group was $7.64 \pm 1.39 \mathrm{hrs}$. and in fentanyl group was $6.04 \pm 1.29 \mathrm{hrs}$. Statistically, the difference is highly significant with ' $p$ ' value $(<0.001)$. Thus, fentanyl prolongs duration of analgesia more than butorphanol. Similar to our study, Kaur et al in 2014 compared epidural butorphanol and fentanyl as adjuvants in lower abdominal surgery and concluded mean duration of analgesia in butorphanol group was $7.64 \pm 1.41 \mathrm{hrs}$. and $5.96 \pm 1.30 \mathrm{hrs}$. in fentanyl group. ${ }^{[8]}$

Our results are in concordance with Naulty et al in 1985 observed duration of analgesia with epidural fentanyl 100 mcg to be about $4.6 \mathrm{hrs}$.[13]

\section{CONCLUSION}

The mean onset of sensory blockade and time for maximum sensory blockade was observed to be significantly reduced with the addition of fentanyl to bupivacaine as compared to butorphanol to bupivacaine. The results showed statistically significant increase in the duration of analgesia with the addition of fentanyl to bupivacaine as compared to butorphanol to bupivacaine. However, haemodynamic parameters and level of sedation was comparable in both groups.

So, we can conclude that butorphanol and fentanyl were effective adjuvants to bupivacaine when used epidurally in patients undergoing lower limb surgery. Although, epidural fentanyl with bupivacaine produces significantly faster onset of sensory blockade compared to epidural butorphanol; however, epidural butorphanol with bupivacaine produces significantly prolonged duration of analgesia compared to epidural fentanyl.

\section{REFERENCES}

[1] Datta S, Alper MH, Ostheimer GW, et al. Method of ephedrine administration and nausea and hypotension during spinal anesthesia for cesarean section. Anesthesiology 1982;56(1):68-70.

[2] Naulty JS, Weintraub S, McMahon, et al. Epidural butorphanol for post-cesarean delivery pain management. Anesthesiology 1984;61(3):A415.

[3] Chaithanya K, Reddy N, Gandra S, et al. A comparative study of the effect of epidural bupivacaine $(0.125 \%)$ versus epidural bupivacaine $(0.125 \%)$ and butorphanol $(2 \mathrm{mg})$ for post-operative pain relief in lower abdominal and lower limb surgeries. JEMDS 2014;3(35):9243-9.

[4] Miller RD. Anaesthesia for thoracic surgery. Chap- 66. In: Miller's anaesthesia. Vol. 2. $8^{\text {th }}$ edn. Churchill Livingstone Elsevier 2015: p. 2002.

[5] Wolfe MJ, Davies GK. Analgesic action of extradural fentanyl. Br J Anaesthesia 1980;52(3):357-8.

[6] Houlton PG, Reynolds F. Epidural diamorphine and fentanyl for post-operative pain. Anaesthesia 1981;36(12):1144-5.

[7] Rutter DV, Skewes DG, Morgan M. Extradural opioids for post-operative analgesia: a double blind comparison of pethidine, fentanyl and morphine. $\mathrm{Br} J$ Anaesthesia 1981;53(9):915-20.

[8] Kaur J, Bajwa SS. Comparison of epidural butorphanol and fentanyl as adjuvants in the lower abdominal surgery: a randomized clinical study. Saudi J Anaesth 2014;8(2):167-71.

[9] Kumar S, Lokesh KKS, Rajalakshmi J. A comparative study of epidural bupivcaine with buprenorphine and bupivacaine with fentanyl in lower limb surgeries. IOSR Journal of Dental and Medical Sciences 2014;13(12):23-8.

[10] Sharma D, Haleem S, Tauheed N, et al. Clonidine or butorphanol as an adjuvant to epidural bupivacaine in orthopaedic surgery - a comprative analysis of the quality and duration of anaesthesia. Ann Int Med Den Res 2015;1(3):229-33.

[11] Nupoor N, Talikoti AT, Kumar PBR, et al. Epidural bupivacaine with dexmedetomidine or fentanyl for lower abdominal and lower limb surgeries - a randomized prospective study. Journal of Clinical and Biomedical Sciences 2016;6(1):14-9.

[12] Hunt CO, Naulty JS, Malinow AM, et al. Epidural butorphanol-bupivacaine for analgesia during labor and delivery. Anesth Analg 1989;6(3):323-7.

[13] Naulty JS, Datta S, Ostheimer GW, et al. Epidural fentanyl for postcesarean delivery pain management. Anesthesiology 1985;63(6):694-8. 